\title{
Effect of Reading Habits on the Academic Performance of Students: A Case Study of the Students of Afe Babalola University, Ado-Ekiti, Ekiti State
} \author{
Ogbuiyi Sussan Udoaku ${ }^{3}$ \\ ${ }^{1}$ Afe Babalola University Library, Afe Babalola University, Ado-Ekiti, Nigeria \\ ${ }^{2}$ Achievers University Library, Achievers University, Owo, Nigeria \\ ${ }^{3}$ Babcock University Library, Babcock University, Illisan-Remeo, Nigeria
}

Oriogu Chuks Daniel ${ }^{1}$, Subair Roselyn Esoname ${ }^{1}$, Oriogu-Ogbuiyi Darlina Chima ${ }^{2}$,

Email address:

oriogucd@abuad.edu.ng (Oriogu C. D.), subairre@abuad.edu.ng (Subair R. E.), chimadarlina@yahoo.co.uk (Oriogu-Ogbuiyi D. C.), ogbuiyis@babcock.edu.ng (Ogbuiyi S. U.)

\section{To cite this article:}

Oriogu Chuks Daniel, Subair Roselyn Esoname, Oriogu-Ogbuiyi DarlinaChima, Ogbuiyi Sussan Udoaku. Effect of Reading Habits on the Academic Performance of Students: A Case Study of the Students of Afe Babalola University, Ado-Ekiti, Ekiti State. Teacher Education and Curriculum Studies. Vol. 2, No. 5, 2017, pp. 74-80. doi: 10.11648/j.tecs.20170205.13

Received: April 15, 2017; Accepted: May 8, 2017; Published: October 6, 2017

\begin{abstract}
Reading is vital in the life of every student. It is germane to academic performance of students. Imbibing reading habits will help them become lifelong learners. The study investigated the effect of reading habit on the academic performance of students of Afe Babalola University, Ado-Ekiti, Nigeria. Five research questions guided the study. The study adopted survey research method. The research instrument used was structured questionnaire. The findings show that majority of the respondents who took part in the study are not used to their time for reading and they purposely read for examination, self development and for developments of spoken and written English. The respondents mostly read notebooks, textbooks and electronic resources. The study also revealed that reading habits has significance effect on academic performance of students. The major factor militating against students reading habit is the Social media e.g. Facebook, Whatsapp, Twitter, 2go etc. Therefore, the study recommends that students should be encouraged by their lectures to read different information resources other than their notebooks and handouts, they should have a blueprint of their time schedule for reading and also academic institutions should monitor use of social media, so that students will meticulously use it for educational purposes.
\end{abstract}

Keywords: Reading, Reading Habits, Academic Performance

\section{Introduction}

Reading is the fundamental process of learning. It is the practice of comprehending and acquiring knowledge for personal growth and development. It is an essential process that aids the conception of thoughts and knowledge in ones chosen field of study or specialization. [1] assert that the ability to read is at the heart of self-education and lifelong learning and that it is an art capable of transforming life and society. Therefore, for students in tertiary institutions to perform well in their academic pursuit, reading is the basis to effective learning. Reading habits will enable students to have effective study skills, knowledge of different information resources, and effective retention capacity. Reading is an essential tool for knowledge transfer and the habit of reading is an academic activity that increases skills in reading strategies [2]. Thereof, cultivating reading habits is tantamount to students academic performance.

According to [3] academic success at the tertiary level is likely a multidimensional phenomenon that includes languages proficiency, learning, study strategies and certain personal characteristics. And this could be achieve when one imbibe a good reading habits which will make him/her a lifelong learner. Early imbibing of reading habits is an essential skill necessary in the acquisition of knowledge which is highly demanding in the life of every student in the academic environment. No wonder [4] asserts that, it is best 
formed at a young impressionable age in school, but once formed it can last one's life time. Hitherto, whenyoungpeople miss the opportunity of appreciating and loving to read, at early stage, they will find it challenging to imbibe reading habit in later years. Therefore, the study investigates effect of reading habit on the academic performance of students of Afe Babalola University

\section{Literature Review}

Reading is a prerequisite of effective study habit which will help to improve students' academic performance. It is the hallmark of success, not just in the academic environments but a means to lifelong learning. Reading is the catalyst to career progression and academic achievements. Therefore for a person to diligently dig deeply to the root of knowledge and its enduring gift; is through reading. According to [5] reading is regarded as a process, a mode of thinking, a kind of real experience and involves many complex skills: the ability to perceive printed words, to skim for information and then perhaps read intensively. [6] affirms that through reading, humans have the tools to transmit knowledge to each succeeding generation; it does allow one to listen to the wisdom and people of the ages. [7] assert that reading is a skill that must be nurtured from a child's earliest years and the habit of reading should begin at an early stage and should be imbibed throughout one's lifetime. However, reading is a persistent activity of day to day training that evolves into a habit and eventually a culture. In the views of [8] it should be more of reasoning, involving the meaningful interpretation of words, phrases and sentences, requiring all types of thinking such as critical, analytical, creative, imaginative, evaluative, judgemental and problem-solving. Reading is an effortful activity that often involves choice, motivation is crucial to reading engagement [9]. A candid advice from [10] is the more students read the better they read, and the better they read the more they read. According to [11] "... reading is an intellectual action which is possible only if a man has formed a habit of reading and practicing it since childhood". [12], in his article on developing a reading culture, proposed:

that if we identify an important goal of ... reading programs for college readers as providing a foundation of life-long reading, a study-skills approach to college development reading falls short. Instead, we must focus on encouraging and instilling in ... students the belief that reading has intrinsic value. It is through this approach that solid academic progress can be obtained as well.

Thereby cultivating a reading habit is a necessity in the development of intellectual capacity and capability of students. One ongoing way to acquire new knowledge is to develop the habit of reading, which "develops a capacity for focused attention and growth" [13]. [14] assert that reading habit is the cultivation of an attitude and the possession of skills that makes reading pleasurable, regular and a consistent activity. It is a positive attitude and regular skill developed towards reading. Shen [15] identifies reading habits, as how often, how much, and what the readers read. [16] study on reading habits revealed that, whenever a student adopts effective reading habit, his learning skills, his understanding of learning materials and his memory processing both test and examination are improved appreciably. Also [16] maintains that people's achievement is functional to her perception of the self and the individual is motivated by a need to achieve at a level which is consisted with his or her current habits. [17] asserts that the credit of an educational system depends on the learning of its learners. As this depend on the ability of students to effectively comprehend with high concentration ability through cultivating good reading habit. [19], further described man as a creator of habits. He states that man has the ability to create habits that will enable him achieve pressing needs hence; he can form habits of study, emotional control, habitual attitudes and habit of consumption. Therein, "success in college depends to a considerable degree upon students' ability to engage in strategic reading of extensive academic or informational [20]. The improvement of academic performance of students is one of the fundamental objectives of any educational institution whose core vision is to develop human in character and excellence through teaching and research.

In the view of [21] poor reading skills which has been identified as the problem of Nigerian students and was as a result of the following: slow comprehension rate, slow reading rate, difficulty in distinguishing main ideas from irrelevant details, inadequate vocabulary or word power, inadequate reading interests and habits, distractions from television and film viewing and lack of interest and relevant reading materials. In Nigeria, a study carried out by [22], reveals that 40 percent of adult Nigerians never read a non-fiction book from cover to cover after they finished school. The average Nigerian reads less than one book per year, infact only one percent of successful men and women in Nigeria read one nonfiction book per month. In the same study, 30 million Nigerians have graduated from high school with poor reading skills. Therefore, there is a basic social divide between those whom life is an accrual of fresh experience and knowledge, and those for whom maturity is a process of mental atrophy. The shift toward the latter is frightening [23]. There is a great decline in reading habit of students, in which The National Endowment for the Arts [13] reported that reading in America is becoming less common. Studies in Malaysia also reported that Malaysian students read very little [24]. In Nigeria, [25] came to a grime conclusion that there is a high decline rate in the reading culture.

Reading is not just about printed matter, but about the ability to interpret anything that is intended to convey a message or that which is to enable communication [26]. The advent of the Internet has revolutionalized the reading habits of students and its dominance is quite prevailing among the young people. With the growing amount of digital information available, people particularly young adults are found spending more time reading electronic materials [27]; [28]. However, the Internet has created an enabling platform where students can access information materials around the 
world at any location. A good amount of research can also be found looking for changes in reading patterns due to the widespread use of the Internet and the use of alternative reading resources notably using hypertexts and multimedia resources [27]. [29] opined that while the Internet is a textsaturated world, reading online screens tends to be significantly different from reading printed text. A lot of studies have shown the level of students preference to Internet resources, but there is still a perturbing issue, that the Internet have greatly influenced students reading habit negatively in which the now focus on social media for mainly chatting with friends and other activities not tailored towards academic purpose which has made them "reluctant readers", and invariably may lead to poor academic performance.

Therefore, academic libraries as matter of fact should endeavour to provide adequate information materials (both print and non-print) and ensure convivial and conductive atmosphere suitable for students to study and read without distractions. Also they should try to implement Internet monitoring policy, so that students will meticulously use it for academic purpose. Thereof, a challenge for educators is to reinforce students who have the reading habit, fueled by motivation, then encourage unmotivated students to acquire the lifelong habit of reading [30]; he also assert that just as all teachers are teachers of reading, all teachers must also encourage and model the habit of lifelong reading and learning. Therein, motivating and encouraging students to read should be a collaborative effort of the librarians, educators and parents in order to build more responsible citizens. This is why the study investigates effect of reading habit on the academic performance of students of Afe Babalola University.

\section{Objectives of the Study}

The main objective of this study is to investigate the effect of reading habit on the academic performance of students of Afe Babalola University. The specific objectives of the study are to:

1. determine the time spent by students on reading;

2. ascertain the purpose of reading by students;

3. determine the types of information materials mostly read by students;

4. examine the reading habits of students;

5. find out factors militating against students reading habit.

\section{Research Hypotheses}

In order to achieve the objectives of the study, the following null hypotheses are to be tested.

Ho: There is no significant effect of students reading habits on academic performance.

Hi: There is significant effect of students reading habits on academic performance.

\section{Methodology}

Descriptive survey research method was adopted for the study and structured questionnaire was used to collect data. A total of two hundred (200) students of Afe Babalola university library users were sampled, out of which one hundred and eighty (180) was completed for analysis using frequency counts, simple percentage, mean, standard deviation, to answer the research questions. Thus, Random sampling technique was used to administer the questionnaire.

\section{Analysis of Findings}

Table 1. Distribution of respondents by college.

\begin{tabular}{lll}
\hline College & Frequency & Percentage \\
\hline Engineering & 17 & 9.4 \\
Law & 52 & 28.9 \\
SMS & 62 & 34.4 \\
Medicine \& Health Science Sciences & 49 & 27.2 \\
Total & 180 & 100 \\
\hline
\end{tabular}

The data presented in table 1 shows that 17 respondents which represent 9.4 percent were from college of Engineering. In the college of Law there were 52 respondents which represent 28.9 percent while 62 respondents which represent 34.4 percent were from college of Social and Management Sciences, also in the college of medicine and Health Sciences were 49 respondents which represent 27.2 percent.

Table 2. Distribution of Respondents by Level.

\begin{tabular}{lll}
\hline Level & Frequency & Percentage \\
\hline 100 & 30 & 16.7 \\
200 & 48 & 26.7 \\
300 & 54 & 30.0 \\
400 & 31 & 17.2 \\
500 & 9 & 5.0 \\
PG Students & 8 & 4.4 \\
Total & 180 & 100 \\
\hline
\end{tabular}

The data presented in table 2 shows that 16.7 is of the students who took part in the study were in 100 level. 26.7 were in 200 levels, 30.0 were in 300 level and 17.2 were in 400 level respectively while 5.0 and 4.4 were in 500level and postgraduate students

Table 3. Distribution by Gender.

\begin{tabular}{lll}
\hline Gender & Frequency & Percentage \\
\hline Male & 74 & 41.1 \\
Female & 106 & 58.9 \\
Total & 180 & 100 \\
\hline
\end{tabular}

Table 3 revealed that the majority of the students who took part in the study $(58.9 \%)$ were female while $41.1 \%$ of the students who use library were male.

Table 4. Distribution by Age of Students.

\begin{tabular}{lll}
\hline Age & Frequency & Percentage \\
\hline $15-18$ & 71 & 39.4 \\
$19-21$ & 71 & 39.4 \\
$22-24$ & 22 & 12.2 \\
25 above & 16 & 8.9 \\
Total & 180 & 100 \\
\hline
\end{tabular}

Table 4 revealed that $39.4 \%$ of the students who took part 
in the study were between $15-18$ and $19-21$ years. $12.2 \%$ were between $22-24$ years while only $8.9 \%$ were range of 25years and above. This result suggests that some postgraduate students of Afe Babalola University took part in the study are slightly above 25 years.

Table 5. Time Spent on Reading

\begin{tabular}{lll}
\hline (a) Less than an Hour & Frequency & Percentage \\
Yes & 6 & 3.3 \\
No & 174 & 96.7 \\
(b) 2-4 Hours & Frequency & Percentage \\
Yes & 85 & 47.2 \\
No & 95 & 52.8 \\
(C) 4-6 Hours & Frequency & Percentage \\
Yes & 74 & 41.1 \\
No & 108 & 58.9 \\
Above 6 Hours & Frequency & Percentage \\
Yes & 15 & 8.3 \\
No & 165 & 91.7 \\
\hline
\end{tabular}

From the table above 6 respondents out of 180 respondents which is $3.3 \%$ of the students which took part in the study were reading less than an hour while majority $(96.7 \%)$ were reading more than an hour. Also in the table bin the above analysis shows that $47.2 \%$ of the study were reading between an hours of 2-4 which represent 85 respondents out of 180 of the students who took part in the study while $52.8 \%$ of them say no to the question, thus implies that they are not reading up to 3-4 hours. $41.1 \%$ of the respondents were reading between 4-6 hours while $58.9 \%$ of them were not reading up to those hours.

Finally, the students were asked to indicate whether they are reading above 6 hours majority of them (91.7\%) reported that they do not while $8.3 \%$ of them said they read above 6 hours.

Table 6. Purpose of Reading

\begin{tabular}{|c|c|c|c|c|c|c|}
\hline PURPOSE OF READING & SA (\%) & A \% & D \% & SD \% & Mean & SD \\
\hline For examination & $102(56.7)$ & $44(24.4)$ & $15(8.3)$ & $19(10.6)$ & 1.728 & 1.002 \\
\hline For self-development & $104(57.8)$ & $52(28.9)$ & $13(7.3)$ & $11(6.1)$ & 1.617 & 0.867 \\
\hline For assignment and coursework & $60(53.3)$ & $104(57.8)$ & $8(4.2)$ & $8(4.4)$ & 1.800 & 0.7200 \\
\hline For pleasure and relaxation & $45(25.0)$ & $43(23.9)$ & $61(33.9)$ & $31(17.2)$ & 2.433 & 1.047 \\
\hline To improve spoken/written English & $38(21.1)$ & $71(39.4)$ & $47(26.1)$ & $24(13.3)$ & 2.317 & 0.954 \\
\hline To impress my parents & $41(22.8)$ & $37(20.6)$ & $64(35.6)$ & $38(21.1)$ & 2.550 & 1.064 \\
\hline To while away time & $9(5)$ & $37(20.6)$ & $62(34.4)$ & $72(40)$ & 3.094 & 0.895 \\
\hline
\end{tabular}

Table 4 shows the rating of the items on the purpose of reading as follow: For examination $($ Mean $=1.728$ ), For self development $($ Mean $=1.617)$, For assignment and coursework $($ Mean $=1.800)$, For pleasure and relaxation $($ Mean $=2.433)$, To improve spoken/written English (Mean = 2.317), To impress my parents (Mean = 2.550), and lastly followed by To while away time (Mean $=3.094)$.

Table 7. Reading Habits of Students.

\begin{tabular}{|c|c|c|c|c|c|c|}
\hline READING HABITS OF STUDENTS & SA \% & $\mathbf{A} \%$ & D \% & SD \% & Mean & SD \\
\hline I read only as the need arises & $39(21.7)$ & $52(28.9)$ & $54(30)$ & $35(19.4)$ & 2.472 & 1.038 \\
\hline The library is my favourite reading place & $51(28.3)$ & $76(42.2)$ & $35(19.4)$ & $18(10)$ & 2.111 & 0.933 \\
\hline I am more interested in reading my class/lecture notes & $42(23.3)$ & $81(45)$ & $40(22.2)$ & $17(9.4)$ & 2.178 & 0.898 \\
\hline I prefer reading electronic materials to print materials & $36(20)$ & $72(40)$ & $45(25)$ & $27(15)$ & 2.350 & 0.966 \\
\hline $\begin{array}{l}\text { Formal features of a book (thickness, font size, illustrations, etc.) } \\
\text { affect my preference for reading it or not. }\end{array}$ & $40(22.2)$ & $62(34.4)$ & $44(24.4)$ & 34 (18.9) & 2.400 & 1.034 \\
\hline $\begin{array}{l}\text { I initially learn about the book I will read, if my friends who has read } \\
\text { it or it is recommended for a particular course by my lecturer }\end{array}$ & $37(20.6)$ & $90(50)$ & $28(15.6)$ & 25 (13.9) & 2.227 & 0.933 \\
\hline
\end{tabular}

Table 4 shows the rating of the items on the reading habit of students as follow: I read only as the need arises (Mean $=$ 2.472), The library is my favourite reading place (Mean = 2.111), I am more interested in reading my class/lecture notes $($ Mean $=2.178)$, I prefer reading electronic materials to print materials $($ Mean $=2.350)$, Formal features of a book (thickness, font size, illustrations, etc.) affect my preference for reading it or not (Mean $=2.400$ ), and lastly followed by I initially learn about the book I will read, if my friendswho has read it or it is recommended for a particular course by my lecturer $($ Mean $=2.227)$.

Table 8. Types of Materials Mostly Read.

\begin{tabular}{lllllll}
\hline TYPES OF MATERIALS MOSTLY READ & SA\% & A\% & D\% & SD\% & Mean & SD \\
\hline Notebooks & $112(62.2)$ & $52(28.9)$ & $9(5)$ & $7(3.9)$ & 1.506 & 0.766 \\
Textbooks & $65(36.1)$ & $81(45)$ & $24(13.3)$ & $10(5.6)$ & 1.883 & 0.841 \\
Novels & $39(21.7)$ & $47(26.1)$ & $63(35)$ & $31(18.3)$ & 2.478 & 1.016 \\
Newspapers and Magazines & $22(12.2)$ & $42(23.3)$ & $79(43.9)$ & $37(20.6)$ & 2.728 & 0.926 \\
E-resources & $68(37.8)$ & $80(44.4)$ & $23(12.8)$ & $9(5)$ & 1.850 & 0.829 \\
\hline
\end{tabular}

Table 8 shows the rating of the items on the types of information resources mostly readas follow: Notebooks $($ Mean $=1.506)$, Textbooks $($ Mean $=1.883)$, Novels $($ Mean $=2.478)$, Newspapers/Magazines $(\mathrm{Mean}=2.728)$, and e-resources $($ Mean $=1.850)$. 
Table 9. Factors Militating Against Students Reading Habit.

\begin{tabular}{|c|c|c|c|c|c|c|}
\hline ITEMS & SA\% & $\mathbf{A} \%$ & D\% & SD\% & Mean & SD \\
\hline Inadequate information resources in the library & $37(20.6)$ & $41(22.8)$ & $63(35)$ & $39(21.7)$ & 2.589 & 1.039 \\
\hline Lack of interesting and current reading materials & $48(26.7)$ & $43(23.9)$ & $61(33.9)$ & $28(15.6)$ & 2.383 & 1.043 \\
\hline Unpaid tuition & $14(7.8)$ & $11(6.1)$ & $70(38.9)$ & $85(47.2)$ & 3.256 & 0.885 \\
\hline Social media e.g. Facebook, Whatsapp, Twitter, 2 go etc. & $69(38.3)$ & $55(30.6)$ & $29(16.1)$ & $27(15)$ & 2.522 & 0.936 \\
\hline Much time spent on television watching and playing games & $24(13.3)$ & $41(22.8)$ & $68(37.8)$ & $47(26.1)$ & 2.767 & 0.987 \\
\hline Hostilityof library staff & $9(5)$ & $24(13.3)$ & $90(50)$ & $57(31.7)$ & 3.083 & 0.804 \\
\hline Distraction from opposite sex & $8(4.4)$ & $26(14.4)$ & $68(37.8)$ & $78(43.3)$ & 3.200 & 0.848 \\
\hline
\end{tabular}

Table 9 reveals the rating of the items on the factors militating against reading habit of students as follow: Inadequate information resources in the library (Mean = 2.589), Lack of interesting and current reading materials $($ Mean $=2.383)$, Unpaid tuition $($ Mean $=3.256)$, Social media (Mean = 2.522), Much time spent on television watching and playing games (Mean $=2.767)$, Hostility of library staff $($ Mean $=3.083)$ and Distraction from opposite $\operatorname{sex}($ Mean $=3.200)$.

Table10. Relationship Between Reading and Academic Performance.

\begin{tabular}{llllll}
\hline Statement & $\mathbf{X}$ & $\mathbf{Y}$ & $\mathbf{X}^{\mathbf{2}}$ & $\mathbf{X Y}$ & $\mathbf{Y}^{\mathbf{2}}$ \\
\hline 1 & 91 & 89 & 828 & 8099 & 7921 \\
2 & 127 & 53 & 16129 & 6731 & 2809 \\
3 & 123 & 57 & 15129 & 7011 & 3249 \\
4 & 108 & 72 & 11664 & 7776 & 5184 \\
5 & 102 & 78 & 10404 & 7956 & 6084 \\
6 & 127 & 53 & 16129 & 6731 & 2809 \\
$\Sigma$ & 678 & 352 & 77736 & 37954 & 25256 \\
\hline
\end{tabular}

$$
\begin{gathered}
X=\frac{678}{6}=113 \\
Y=58.7 \\
b=\frac{\sum x y-n X Y}{\sqrt{\sum^{2}-n X^{2}}} \\
b=\frac{37954-6 \times 133 \times 58.7}{77736-6 \times 133 \times 133} \\
b=1.62 \\
a=Y-b X \\
a=58.7-(-1.62)(113) \\
58.7+183.06=241.76
\end{gathered}
$$

Testing the Significance of $b$

$$
\begin{gathered}
\mathrm{Sb}=\frac{\sqrt{\sum y^{2}-a \sum y-b \sum x y}}{n-2} \\
=\frac{\sqrt{\sum x^{2}-n X^{2}}}{6-2} \\
\sqrt{77736-6(113)^{2}} \\
=\frac{\sqrt{1641.96}}{4} \\
\sqrt{1122}
\end{gathered}
$$

$$
\begin{gathered}
=\frac{10.130}{33.496}=0.302 \\
\mathrm{Sb}=0.302 \\
\therefore / \mathrm{t} /=\frac{1.62}{0.302}=5.36
\end{gathered}
$$

Critical 2 table at 4 degree of 5\% level of significance to two tarled tap is I, 2.776

Decision

$$
5.36>2.776
$$

Since 5.36 is greater than 2.77 , therefore we reject Ho which states that there is no significance effect of students reading habits on academic performance. We hereby conclude that reading habits has significance effect on academic performance on the students.

\section{Discussion of Findings}

The findings reveals that majority of the respondents are female students and the respondents are mainly between the age bracket of (15-18) and (19-21) respectively. From the findings, it can be deduce that majority of the students who took part in the study are not used to their time for reading. Based on the purpose of reading, majority of the respondents mainly read for examination, self development and for developments of spoken and written English. [31] and [32] reported that majority of students read their lecture notes and handouts with the main purpose of passing their examination, while very few read to satisfy recreational interest or intellectual curiosity. On the reading habits of the respondents, most of the respondents indicated that the library is their favourite place of reading, they are more interested in reading their class/lecture notes, the formal features of a book (thickness, font size, illustrations, etc.) affect preference for reading it or not, and they initially learn about the book the will read, if friends who has read it or it is recommended for a particular course by the lecturer. However, the types of information materials mostly read by the respondents are basically their notebooks, textbooks and electronic resources. Based on the findings, the major factors militating against students reading habit is the Social media e.g. Facebook, Whatsapp, Twitter, 2go etc. Finally, the study also revealed that reading habits has significance effect on academic performance on the students. This is line with the study by [33], [2] and [34] that reading habit has significance influence on academic performance and there is a relationship between reading habit and academic performance. 


\section{Conclusion and Recommendations}

Reading is vital in the life of everyone, it emancipate man from the shackles of ignorance. It is an effective means to assimilate and comprehend knowledge for personal growth and advancement. Imbibing reading habit will prepare students to a more responsible and independent life. Therefore to be highly focus, versatile and knowledgeable in the course of life; students need to cultivate the habit of readings. As reading has been highly acknowledge by different authors as an influencing factor to academic performance. Therefore, the study recommends that:

(1) Students should be motivated and encouraged by their lectures to read different information resources other than their notebooks and handouts so as to be exposed to diverge and broader views to knowledge.

(2) Academic institutions should be encourage students to have a blueprint of their time schedule for reading

(3) Academic institutions should monitor abuse of use of social media, so that students will meticulously use it for educational purposes.

\section{References}

[1] Tella, Adenyinka; \&Akande, Samson. (2007). Children's reading habits and availability of books in Botswana primary schools: Implications for achieving quality education. The Reading Matrix, 7 (2). Retrieved 10 November 2015 from: http://www.readingmatrix.com/articles/adeyinka/article.pdf.

[2] Owusu-Acheaw, M., and Larson, A. G (2014) Reading Habits Among Students and its Effect on Academic Performance: A Study of Students of Koforidua Polytechnic". Library Philosophy and Practice (e-journal). Retrieved on $10^{\text {th }}$ April 2017 fromhttp://digitalcommons.unl.edu/libphilprac/1130.

[3] Akabuike, I. G and Asika, I. E. (April, 2012) Reading Habits of Undergraduates and their Academic Performances: Issues and Perspectives. An International Multidisciplinary Journal, Ethiopia, 6 (2): 246-257. Retrieved on $11^{\text {th }}$ April, 2017 from DOI://dx.doi.org/10.4314/afrrev.v6i2.22.

[4] Greene, B. (2001) Testing reading comprehension of theoretical discourse with close" Journal of Research in Reading. 24 (1): 32-98.

[5] Karim, N. S. A. and Hasan, H. (2007) Reading habits and attitude in the digital age: Analysis of gender and academic program differences in Malaysia. The Electronic Library, 25 (3): $285-298$. Retrieved on $11^{\text {th }}$ April, 2017from DOI $10.1108 / 02640470710754805$.

[6] Okebukola, F. O. (2004) Reading: key to lifelong development. A key note address delivered at the workshop on readership promotion campaign organized by the National Library of Nigeria.

[7] Aina, A. J., Ogungbeni, J. I., Adigun, J. A. and Ogundipe, T. C. (2011) Poor Reading habits among Nigerian: the role of libraries. Library Philosophy and Practice (e-journal) Paper 529. Retrieved March 23, 2017 from http://digitalcommons.unl.edu/libphilprac/529.

[8] Okwilagwe, O. A. (1998) A New Approach to Reading
Comprehension and Summary for schools and colleges. Ibadan: Sterling - Horden Publishes (Nig) Ltd.

[9] Wigfield, A., Guthrie, J. T., Tonks, S., \& Perencevich, K. C. (2004) Children's motivation forreading: Domain specificity and instructional influences. Journal of Educational Research, 97 (6): 299-309.

[10] Trelease, J. (2001) The read-aloud handbook. Retrieved September $16^{\text {th }} 2016$, from.com/rah_chptl_pl.html.

[11] Fisher B. (2001) Towards increased female participation in science and technology in Nigeria schools. A book of reading the word council for curriculum and instruction. Lagos: Jos Publisher, pp. 206-211.

[12] Paulson, E. J. (2006). Self-selected reading for enjoyment as a college developmental reading approach. Journal of College Reading and Learning, 36 (2): 51-58.

[13] National Endowment for the Arts. (2004) NEA report: Reading at risk. Arts Education Policy Review, 106 (1), 38-39.

[14] Obada, A. M. (2011) Reading culture in Nigeria: A librarian's perspective. Ondo: Covena House Publishers, 53.

[15] Shen, L. (2006) Computer technology and college students' reading habits. Chia-Nan Annual Bulletin, 32, 559-572.

[16] Onyejiaku, F. O. (1987) Techniques of effective study: A manual for students in colleges and universities, Calabar, Wusen Press.

[17] Roth, R. M. (1992) Under achieving students and guidance. Houghton: Miffen Press.

[18] Mashayekhi, F., Shideh Rafati2, Mashayekhi, M., Rafati, F. Mohamadisardoo, M. R. and Yahaghi, E. (2014) The relationship between the study habits and the academic achievement of students in Islamic Azad University of Jiroft Branch. International Journal of Current Research and Academic Review. Vol. 2 (6 June-2014): 182-187.

[19] Denga, A. M. (2001) The effect of study habits on academic performance of Business Education studentsin tertiary institutions of Rivers State. Unpublished bachelors degree project, University of Port Harcourt, Rivers State.

[20] Caverly, D. C., Nicholson, S. A., \& Richard Radcliffe, R. (2004). The effectiveness of strategic reading instruction for college developmental readers. Journal of College Reading and Learning, 35 (1): 25-49.

[21] Nssien, F. U (2007) "Reading Habits and Skills" In F. E. Etim and F. U. Nssien (eds.) Information Literacy for Library Search, Uyo: Abaam Publishing, pp 90-105.

[22] Henry, P. (2004) Children reading habits and their use of media: Exhaustive suggestions on encouraging reading habits among Children”. (e-journal). Paper 529. Nigeria: Lagos State University.

[23] Solomon, A. (2004, July 10). The closing of the American book. The New York Times, p. 33.

[24] Kaur, S. \&Thiyagarajah, R. (1999) The English reading habits of ELLS Students in University Science Malaysia. Paper presented at the Sixth International Literacy and Education Research Network Conference on Learning, Bayview Beach Resort, Penang, Malaysia27-30September 1999. 
[25] Ifedili, C. J. A. (2009) An assessment of reading culture among students in Nigerian tertiaryinstitution - achallenge to educational managers. Reading Improvement, 46 (1).

Retrievedon $11^{\text {th }}$ April,

2017 fromhttp://www.freepatentsonline.com/article/ReadingImprovement/218120730.html.

[26] Onovughe, O. G. (2012) Internet use and reading habits of higher institution students. Journal ofEmerging Trends in Educational Research and Policy Studies, 3 (1): 11-15.

[27] Liu, Z. (2005), "Reading behavior in the digital environment: changes in reading behavior over thepast 10 years", Journal of Documentation, 61 (6): 700-12.

[28] Ramirez, E. (2003), "The impact of the internet on the reading practices of a university community: The case of UNAM", paper presented at the World Library and Information Congress: 69th IFLAGeneral Conference and Council, Berlin, August 1-9.

[29] Cull, Barry. (2011). Reading revolution: Online digital texts and implications for reading inacademics. First Monday, 16 (6-6, June).
[30] Camp, D. (2007) Who's reading and why: Reading habits of lst grade through graduate students. Reading Horizons, 47 (3): 252-268.

[31] Oyewumi, O. and Ebijuwa, A. S. (2009) Reading culture in an African university: Problems and propects. The Information Manager, 9 (2): 30-35.

[32] Edem, M. B. \& Ofre. T. E. (2010) Reading and internet use activities of undergraduate Students of university of Calabar, calabar, Nigeria. Retrieved March 23, 2017 from find articles. com.

[33] Issa, A. O., Aliyu, M. B., Akangbe, R. B., andAdedeji, A. F. (2012) Reading Interests and Habits of the Federal Polytechnic, OFFA, Students. International Journal of Learning \& Development, 2 (1) 471-482. Retrieved 10 November 2015 from 10.5296/ijld.v2i1.1470.

[34] Egong, A. I. (2014) Reading culture and academic achievement among secondary school students. Journal of Education and Practice, 5 (3): 132-136. 